\title{
Talk weight: An observational study of communication about patient weight in primary care consultations
}

\author{
Anita Laidlaw ${ }^{1 *}$, Calum McHale $^{2}$, Heather Locke ${ }^{3}$ and Jo Cecil ${ }^{4}$
}

${ }^{1}$ Principal Teaching Fellow \& Co-director of the Centre for Higher Education Research, School of Medicine, Population and Behavioural Health Sciences, Medical and Biological Sciences Building, University of St Andrews, North Haugh, St Andrews, Fife, United Kingdom.

${ }^{2}$ PhD Student, School of Medicine, Population and Health Sciences, Medical and Biological Science Building, University of St Andrews, North Haugh, St Andrews, Fife, United Kingdom.

${ }^{3}$ Trainee Health Psychologist, Health Psychology Service for Health and Social Care, NHS Lanarkshire, North Lanarkshire Council, Merry Street, Motherwell, United Kingdom.

${ }^{4}$ Lecturer, School of Medicine, Population and Behavioural Health Sciences, University of St Andrews, Medical and Biological Sciences Building, North Haugh, St Andrews, Fife, United Kingdom.

Short Title: communication about patient weight in primary care

*To whom all correspondence should be addressed

Dr Jo Cecil, School of Medicine,

Population and Behavioural Health Sciences,

University of St Andrews,

North Haugh,

St Andrews,

United Kingdom,

KY16 9TF

Email: jc100@st-andrews.ac.uk

Tel: 01334463541

Fax: 01334467470

Keywords: communication, primary care, consultations, General Practitioners, patients, weight, obesity 
Table 1: Description of patient BMI and frequency of weight mention during consultations

\begin{tabular}{lcc}
\hline BMI Category & Weight mentioned & Weight not mentioned \\
\hline $18.5-24.9$ (Normal range) & 2 & 12 \\
Normal range Total & $\mathbf{2}$ & $\mathbf{1 2}$ \\
\hline $25-29.9$ (Overweight) & 2 & 11 \\
$30-34.9$ (Obese Class I) & 2 & 9 \\
$35-39.9$ (Obese Class II) & 1 & 1 \\
$\geq 40$ (Obese Class III) & 2 & 0 \\
Overweight \& Obese Total & $\mathbf{7}$ & $\mathbf{2 1}$ \\
\hline
\end{tabular}

Table 2: Description of the seven consultations with overweight and obese patients where weight was mentioned.

\begin{tabular}{|c|c|c|c|c|c|c|c|c|}
\hline $\begin{array}{l}\text { Case } \\
\text { No. }\end{array}$ & $\begin{array}{c}\text { BMI } \\
\left(\mathrm{kg} / \mathrm{m}^{2}\right)\end{array}$ & Gender & $\begin{array}{l}\text { Presenting } \\
\text { healthcare } \\
\text { problem / } \\
\text { request }\end{array}$ & $\begin{array}{l}\text { Weight } \\
\text { Discussion } \\
\text { Initiator }\end{array}$ & $\begin{array}{c}\text { Time- } \\
\text { point } \\
\text { Raised } \\
\text { [Total } \\
\text { Session } \\
\text { Time] } \\
\text { (Secs) }\end{array}$ & Response & $\begin{array}{l}\text { Weight Related } \\
\text { Outcome }\end{array}$ & $\begin{array}{c}\text { Patient } \\
\text { Satisfaction } \\
\text { Questionnaire } \\
\text { scores } \\
\text { (Max: 70) }\end{array}$ \\
\hline 1 & 44.12 & $M$ & $\begin{array}{l}\text { Cardiovascular/ } \\
\text { Respiratory }\end{array}$ & GP & $\begin{array}{c}1032.78 \\
{[1391.72]}\end{array}$ & $\begin{array}{l}\text { Patient } \\
\text { reduced } \\
\text { space. }\end{array}$ & No & 63 \\
\hline 2 & 40.39 & $\mathrm{~F}$ & $\begin{array}{l}\text { Musculoskeletal/ } \\
\text { Weight }\end{array}$ & Patient & $\begin{array}{c}135.90 \\
{[1369.96]}\end{array}$ & $\begin{array}{l}\text { GP } \\
\text { provided } \\
\text { space. }\end{array}$ & $\begin{array}{c}\text { Yes } \\
\text { (Referral to } \\
\text { dietician and } \\
\text { physiotherapist) }\end{array}$ & 70 \\
\hline 3 & 39.35 & $\mathrm{~F}$ & Weight & Patient & $\begin{array}{c}17.58 \\
{[552.66]}\end{array}$ & $\begin{array}{l}\text { GP } \\
\text { provided } \\
\text { space. }\end{array}$ & $\begin{array}{l}\text { Yes } \\
\text { (Medication } \\
\text { change and } \\
\text { referral for a } \\
\text { blood test) }\end{array}$ & 60 \\
\hline 4 & 34.72 & M & Respiratory & $\mathrm{GP}$ & $\begin{array}{c}83.50 \\
{[633.00]}\end{array}$ & $\begin{array}{l}\text { Patient } \\
\text { reduced } \\
\text { space }\end{array}$ & No & 53 \\
\hline 5 & 34.08 & $\mathrm{~F}$ & Musculoskeletal & GP & $\begin{array}{c}300.93 \\
{[555.41]}\end{array}$ & $\begin{array}{l}\text { Patient } \\
\text { provided } \\
\text { space }\end{array}$ & No & 60 \\
\hline 6 & 26.56 & M & Musculoskeletal & $\mathrm{GP}$ & $\begin{array}{c}398.86 \\
{[619.01]}\end{array}$ & $\begin{array}{l}\text { Patient } \\
\text { reduced } \\
\text { space }\end{array}$ & No & 57 \\
\hline 7 & 25.96 & $\mathrm{~F}$ & $\begin{array}{l}\text { Medication/ } \\
\text { Cardiovascular }\end{array}$ & Patient & $\begin{array}{c}662.98 \\
{[841.96]}\end{array}$ & $\begin{array}{l}\text { GP } \\
\text { reduced } \\
\text { space. }\end{array}$ & No & 57 \\
\hline
\end{tabular}


Talk weight: An observational study of communication about patient weight in primary care consultations

Keywords: communication, primary care, consultations, General Practitioners, patients, weight, obesity 


\section{Summary}

Obesity is a major public health issue and primary care practitioners are well placed to opportunistically raise the issue of overweight or obesity with their patients. This study investigated the prevalence of weight discussion in primary care consultations with overweight and obese patients, in a practice in Fife, Scotland, and described weight-related communication using video analysis. Weight was raised in $25 \%$ of consultations with overweight and obese patients. GPs initiated weight discussion more often than patients however these attempts were often blocked by patients. Weight-related outcomes were more common when patients initiated the weight discussion. This study confirms the potential of video analysis for understanding primary care weight discussion. It also suggests that GPs may benefit from a communication based intervention to tackle patient blocking behaviours and contributes to the evidence suggesting that interventions targeted to increase the prevalence of weight related discussions with their patients are needed. 


\section{Introduction}

The prevalence of obesity has nearly doubled in the last 30 years to $12 \%$ of the worldwide population and has been labelled a global epidemic (World Health Organisation, 2012). In the US, the prevalence of obesity in adults is $35.7 \%$ (Centers for disease control and Prevention, 2013), whilst in European countries the average prevalence rate of obesity is lower, at 16\% (European Comission: Eurostat, 2011). Within the UK, however, Scotland has been recognised as having one of the highest prevalence of obesity in the world (Steel and Cylus, 2012) with $64.3 \%$ of the adult population identified as overweight and $27.7 \%$ of adults identified as obese (Scottish Government, 2012)

Overweight and obesity substantially increase the risk of developing a number of chronic diseases such as hypertension (Rahmouni et al., 2005), cancer (Pischon et al., 2008), cardiovascular disease (Pérez Pérez et al., 2007) and type 2 diabetes mellitus (Mokdad et al., 2003). Being overweight and obese can also have detrimental effects on psychological health (Talen and Mann, 2009).

According to National Health Service (NHS), Scottish Intercollegiate Guidelines Network (SIGN), and National Institute for Health and Care Excellence (NICE) guidelines on prevention, identification assessment and management of overweight and obesity for staff at general practice surgeries and hospitals, doctors are advised to screen routinely for obesity and to recommend dietary and physical activity related interventions to patients who are obese (NHS, 2010, NHS, 2013a). Primary care health professionals can therefore play an important role in the implementation of weight management programmes (Phillips et al., 2014, Kloek et al., 2014) and are suitably placed to implement such programmes opportunistically and in a patient-centred approach. Despite this, there is growing international evidence that discussion about patient weight and weight-related counselling happens very seldom in primary care (Bleich et al., 2011, Greiner et al., 2008, Michie, 
2007, Sciamanna et al., 2000, Scott et al., 2004, Tham and Young, 2008)and may even have declined over the last two decades (Abid et al., 2004, Kraschnewski et al., 2013).

Many studies examining weight discussion between primary care health professionals, such as General Practitioners (GPs), and patients rely on self-report (Michie, 2007, Sciamanna et al., 2000, Tham and Young, 2008) and gain a limited insight into actual communication behaviour occurring during the consultations. GP communication style can significantly impact upon patient compliance (Vermeire et al., 2001), patient satisfaction (Little et al., 2001, Street et al., 2007) and success in weight related interventions (Michie, 2007). Few studies have directly investigated whether or not GPs implement patient weight management guidelines in the UK or how doctors communicate with overweight patients about their weight to facilitate weight management/loss. Insight into the doctor-patient interaction during the consultation may provide valuable information to improve weight discussion in primary care.

This study investigates weight-related communication between GPs and patients in a rural general practice in Fife, Scotland using video analysis. We assess the prevalence of weight-related discussion with overweight and obese patients and conduct a preliminary analysis of the communication behaviour relating to weight discussions. 


\section{Methods}

\section{Participants}

The study was conducted within one GP practice in rural Fife, Scotland. The practice was small, and as a training practice was familiar with use of video capture. Consenting GPs and adult patients participated in the study. This study was approved by both the NHS East of Scotland research ethics committee and the University of St Andrews teaching and research ethics committee.

\section{Procedure}

During the initial stages of the study design, the GP practice was approached by the senior researchers to participate in a study investigating communication in a primary care setting using video capture. Three GP participants were invited to participate and all were recruited into the study; they were not informed that the research focus was specifically about weight communication in order to prevent contamination and bias. GP participants were debriefed at the end of the study to reveal the aim regarding communication into weight and received specific feedback on their communication as part of the debriefing. Twelve normal consultation sessions (morning or afternoon surgeries) were allocated for video capture within the practice during May 2012. Patients were invited to participate when they either contacted the practice to make an appointment with their GP for one of these sessions, or were allocated an appointment during one of the recording sessions for a routine visit. Interested patients were sent an information sheet and consent forms in the mail prior to their appointment. Video recording equipment was set up within the GPs consultation room and consultations were carried out as usual. The recording equipment was active during the entire consultation unless the patient requested that it was stopped or the GP perceived it was impacting on the progression of the consultation. During any physical examinations only audio was recorded. 


\section{Measures}

Immediately following the consultation, patient height was measured to the nearest $0.1 \mathrm{~cm}$ using a stadiometer (Leicester Stadiometer, Seca) and weight was measured to the nearest $0.1 \mathrm{~kg}$ using a mechanical floor scale (Seca). Body mass index $\left(\mathrm{kg} / \mathrm{m}^{2}\right)$ was derived using the height and weight measurements. Patients completed a patient satisfaction questionnaire (PSQ) to assess their level of satisfaction with the interactions during the consultation (Royal College of General Practitioners, 2011). The questionnaire contained 10 statements for patients to rate their agreement on a sevenpoint likert scale with 70 being the highest possible score.

\section{Analysis}

All video recorded consultations were transcribed and uploaded into The Observer XT 10 (Noldus, 2013) for coding and analysis by one researcher. Preliminary analysis of the videos focused on identifying consultations with overweight and obese patients where weight was mentioned and, in those videos, identifying by whom this was raised. The patients' initial presenting healthcare problem(s) or medication request/review(s) were also identified by the coder and recorded. Thereafter, consultation length was recorded and the sequences of communication behaviours were examined to determine the types of immediate responses to a mention of weight. These responses were classified as either providing space (i.e. using behaviours that encourage discussion about weight) or reducing space (i.e. using behaviours that are not facilitative for discussing weight, such as blocking or reducing scope for further discussion or changing the topic of discussion) as defined by the existing and validated Verona Coding (VR-CoDES) scheme (Del Piccolo et al., 2009) which has been used previously to define emotional sequences to code responses to patient cues and concerns. Any weight related outcomes were identified; weight related outcomes were defined as a referral or enrolment onto any weight management programme or intervention, a referral to any service that would assist diet or physical activity, or a concrete and goal oriented intention on behalf 
of the patient to consider their weight and weight loss. For patients who were not overweight or obese, only data on consultation length and patient satisfaction are presented in this study.

Statistical analyses were conducted using IBM SPSS Statistics 21 software. T-tests and analysis of variance (ANOVA) were used on consultation length and patient satisfaction data respectively. 


\section{Results}

A total of 3 GPs and 46 patients consented to participate in this study. Problems with recording equipment resulted in the loss of data for 3 consultations. One patient refused to provide their weight and therefore their data was also removed. The data from a total of 42 patients are included in this analysis (Table 1). In this sample, $28(66.7 \%)$ patients were identified as being overweight or obese (BMI $\geq 25$ ), with 13 overweight (BMI 25-29.9) and 15 (35.7\%) obese (BMI $\geq 30)$. Twenty-four of the $28(85.7 \%)$ overweight and obese patients discussed chronic or on-going health conditions.

Analysis of the video recorded consultations indicated that weight was mentioned in 7 of the 28 consultations (25.0\%) involving overweight and obese patients and in 2 of the 14 consultations (14.3\%) with normal weight range patients (Table 1). Mention of weight occurred most frequently with obese patients, with 5 of the 7 patients in the obese category (BMI $\geq 30$ ) and 2 in the overweight category (BMI $\geq 25)$.

\section{$<$ Table 1>}

Consultations with overweight and obese patients took longer (664.6 \pm 319.9 seconds), on average, than consultations with normal weight range patients (598.9 \pm 302.2 seconds). This difference was not significantly different $(t(40)=-0.64, p=.53$ ). Of the consultations with overweight and obese patients, 21 consults (75\%) exceeded 8 minutes (NHS, 2013b).

GPs raised the topic of weight in four of the seven consultations where it was mentioned (Table 2). In one of the consultations (Case 5) where the GP raised weight during the middle of the consultation, the patient provided space and discussed weight further. Patients reduced space in the other three consultations where GPs raised the topic (Cases 1, 4, 6). GPs raised weight at varying 
times during the consultation. In cases 5 and 6, the GP raised the topic of weight in the middle of the consultation (i.e. two thirds of the way through the consultation); the GP raised weight near the beginning in case 4 (i.e. in the first third) and near the end in case 1 (i.e. in the final third). There was no weight related outcome (for example, referral to a weight management program or service to assist with diet or physical activity or a patient goal oriented weight loss intention) in any of these four consultations.

In the remaining three consultations where weight was mentioned, patients raised the topic of weight (Table 2). In two of these (Cases 2, 3), the patients raised their weight as a topic at the beginning of the consultation (e.g. within the first third). In both of these consultations weight was discussed and a weight-related outcome was achieved (referral to dietician and physiotherapist in one consultation, and a medication change and referral for a blood test in the other). In the third consultation (Case 7) weight was raised by the patient near the end (e.g. within the final third) of the consultation and in this attempt, the GP reduced space. In this consultation there was no weight related outcome (Table 2).

\section{$<$ Table 2>}

No statistical difference in mean patient satisfaction questionnaire scores was observed between overweight and obese patients $(60.29 \pm 5.93)$ and healthy weight patients $(57.64 \pm 7.29), F(1,40)=$ $1.38, p=.25$. Similarly, no difference in mean patient satisfaction scores was identified between overweight and obese patients who attended consultations where weight was mentioned (60 \pm 5.42) and those overweight and obese patients who did not have weight mentioned during their consultation (56.86 \pm 7.77$), F(1,26)=0.98, p=.33$. 


\section{Discussion}

This study has shown that in primary care consultations with overweight and obese patients, patient weight is seldom being mentioned. This is despite the fact that many of the patients are presenting with chronic and on-going conditions (i.e. musculoskeletal pain, cardiovascular issues) known to be exacerbated by excess weight (Flegal et al., 2002). Lack of weight discussion between obese patients and primary care practitioners can be perceived by patients to suggest that their obesity is not an important health concern (Forhan et al., 2013). Our findings, that primary care consultations with overweight and obese patients rarely involve weight management discussion, support previous studies (Bleich et al., 2011, Greiner et al., 2008, Michie, 2007, Sciamanna et al., 2000, Scott et al., 2004, Tham and Young, 2008), but adds a new dimension to our understanding of weight communication in primary care by employing video-capture to directly record and analyse communication behaviour.

When weight was mentioned between GPs and patients, it was more frequently observed in consultations with high $\mathrm{BMI}$ patients $(\mathrm{BMI} \geq 30$ ). In support of this observation, Tham and Young (2008) found that $90 \%$ of weight discussion occurred with obese individuals with developed comorbid problems and that weight discussion did not occur at all with overweight patients, suggesting that an increase in likelihood of weight discussion was related to increase in patient BMI.

The majority (75\%) of overweight and obese patients in this study exceeded the recommended NHS GP consultation time of 8 minutes (NHS, 2013b). Increased weight is related to multiple health risks and co-morbidities (Knight, 2011) and this may result in time limitation being a barrier to weight discussion in primary care consultation (Foster et al., 2003, Tham and Young, 2008). However this 
study may provide some evidence to suggest that additional time does not necessarily increase the likelihood of weight discussion.

GPs in this study initiated weight discussion more often than their overweight and obese patients. This supports recent qualitative findings from the Netherlands in primary care consultations with overweight and obese patients where practice nurses were more likely to initiate weight related discussions (van Dillen et al., 2013). However, GP's attempts to begin weight discussion with overweight and or obese patients were largely unsuccessful since patients were more likely to reduce space for weight discussion following an attempt from their GP to raise the topic. The findings of this preliminary observational study, based in a single Primary Care Practice, conflict with the conclusions of larger self-report survey studies suggesting that overweight and obese patients wanted their GPs to discuss weight with them and were likely to follow weight recommendations from their GP (Potter et al., 2001, Tan et al., 2006). Our observational data suggest that there is potentially a need for additional training to assist GPs in counteracting this initial barrier to weight management discussion.

Patient attempts to initiate weight discussion, when compared with GP attempts, were more likely to result in a weight related outcome. When raised by the patient at the beginning of the consultation, GPs were likely to discuss weight (provide space) with their patients, however when raised near the conclusion of the consultation the GPs were more likely to block discussion (reduce space). Recent research using behavioural coding techniques and time stamping found that medical students were more likely to block discussion of emotion near the end of interactions with simulated patients (Zhou et al., 2013) suggesting that time pressures may increase blocking behaviours. Weight discussion is perceived as time consuming (Foster et al., 2003, Phillips et al., 2013, Tham and Young, 2008), therefore it may be possible that weight was blocked by the GP as a result of time pressures. 
Previous research has highlighted GPs concern of evoking a negative reaction in patients as a key factor in the avoidance of weight discussion (Hansson et al., 2011, Michie, 2007). The patient satisfaction scores in this study suggest that patients were very satisfied with their GPs communication and no difference in satisfaction was found between consultations with overweight and obese patients in which weight was discussed and those where it was not. This suggests that GP concerns about offending patients may be misplaced and, despite communication around weight occurring in the consultation, patients still appear satisfied with their consultation. The location of the practice, in a small rural community in which the patients may have had good and long relationships with their GP, limits the interpretation of the patient satisfaction questionnaire data.

This was a small preliminary study and therefore its findings may not generalise to all NHS Scotland general practices, albeit the prevalence of overweight in the sample population studied generally reflects levels of overweight in Scotland (Scottish Government, 2012). In addition, the results from this study may be subject to bias as patient or GP behaviour might have been influenced by the very nature of the camera observation, although these effects may be minimal (Themessl-Huber et al., 2008). However, these findings suggest that weight discussion for overweight and obese patients is not routine within primary care practice in Scotland. GPs in this study did initiate weight discussion more often than their patients, but weight outcomes were more common when patients led a weight discussion. GPs may benefit from a communication intervention focused on the management of reducing space behaviours from patients. This study confirms that direct video observation has the potential to provide accurate and objective data on the prevalence of weight discussion in primary care and allow for a detailed examination of the nuances of weight related communication behaviour between GPs and their overweight and obese patients. Improving our understanding of weight management discussion is necessary to facilitate development of communication training interventions to influence practice behaviour related to raising the topic of overweight or obesity with patients and to aid best practice in patient weight management. 


\section{Acknowledgements}

We wish to acknowledge the patients and primary care practitioners who took part in this study. We would also like to acknowledge Professor Gerry Humphris for his discussion on behavioural coding.

\section{Financial Support}

None

\section{Conflicts of Interest}

None

\section{Ethical Standards}

The authors assert that all procedures contributing to this work comply with the ethical standards of the relevant national and institutional guidelines on human experimentation (NHS East of Scotland research ethics committee and the University of St Andrew teaching and research ethics committee) and with the Helsinki Declaration of 1975, as revised in 2008. 


\section{References}

Abid, A., Galuska, D., Khan, L., Gillespie, C., Ford, E. \& Serdula, M. 2004. Are healthcare professionals advising obese patients to lose weight? A trend analysis. MedGenMed: Medscape general medicine, 7, 10-10.

Bleich, S. N., Pickett-Blakely, O. \& Cooper, L. A. 2011. Physician practice patterns of obesity diagnosis and weight-related counseling. Patient Educ Couns, 82, 123-9.

Centers for disease control and Prevention. 2013. Health, United States, 2012.

Del Piccolo, L., Finset, A. \& Zimmermann, C. 2009. Verona Coding Definitions of Emotional

Sequences (VR-CoDES): Cues and Concerns Manual [Online]. Available: http://www.each.nl/.

European Comission: Eurostat. 2011. Overweight and obesity - BMI statistics [Online]. Available: http://epp.eurostat.ec.europa.eu/statistics explained/index.php/Overweight and obesity BMI statistics [Accessed 27 March 2014].

Flegal, K. M., Carroll, M. D., Ogden, C. L. \& Johnson, C. L. 2002. Prevalence and trends in obesity among US adults, 1999-2000. JAMA: the journal of the American Medical Association, 288, 17231727.

Forhan, M., Risdon, C. \& Solomon, P. 2013. Contributors to patient engagement in primary health care: perceptions of patients with obesity. Prim Health Care Res Dev, 14, 367-72.

Foster, G. D., Wadden, T. A., Makris, A. P., Davidson, D., Sanderson, R. S., Allison, D. B. \& Kessler, A. 2003. Primary care physicians' attitudes about obesity and its treatment. Obes Res, 11, 1168-77.

Greiner, K. A., Born, W., Hall, S., Hou, Q., Kimminau, K. S. \& Ahluwalia, J. S. 2008. Discussing weight with obese primary care patients: physician and patient perceptions. J Gen Intern Med, 23, 581-7.

Hansson, L., Rasmussen, F. \& Ahlstrom, G. 2011. General practitioners' and district nurses' conceptions of the encounter with obese patients in primary health care. BMC Family Practice, 12, 7. Kloek, C. J. J., Tol, J., Veenhof, C., van der Wulp, I. \& Swinkels, I. C. S. 2014. Dutch General Practitioners' weight management policy for overweight and obese patients. BMC Obesity, 1, 2. Knight, J. A. 2011. Diseases and disorders associated with excess body weight. Ann Clin Lab Sci, 41, 107-21.

Kraschnewski, J. L., Sciamanna, C. N., Stuckey, H. L., Chuang, C. H., Lehman, E. B., Hwang, K. O., Sherwood, L. L. \& Nembhard, H. B. 2013. A silent response to the obesity epidemic: decline in US physician weight counseling. Med Care, 51, 186-92.

Little, P., Everitt, H., Williamson, I., Warner, G., Moore, M., Gould, C., Ferrier, K. \& Payne, S. 2001. Observational study of effect of patient centredness and positive approach on outcomes of general practice consultations. BMJ: British Medical Journal, 323, 908.

Michie, S. 2007. Talking to primary care patients about weight: A study of GPs and practice nurses in the UK. Psychology, Health \& Medicine, 12, 521-525.

Mokdad, A. H., Ford, E. S., Bowman, B. A., Dietz, W. H., Vinicor, F., Bales, V. S. \& Marks, J. S. 2003. Prevalence of obesity, diabetes, and obesity-related health risk factors, 2001. JAMA: the journal of the American Medical Association, 289, 76-79.

NHS. 2010. 115: Management of Obesity. A national clinical guideline. Scottish Intercollegiate Guidelines Network (SIGN).

NHS. 2013a. Managing overweight and obesity in adults - lifestyle weight management services National Institute for Health and Care Excellence (NICE).

NHS. 2013b. Your choices in the NHS: GP appointments [Online]. Available:

http://www.nhs.uk/choiceintheNHS/Yourchoices/GPchoice/Pages/GPappointments.aspx.

Noldus. 2013. The Observer XT 10 [Online]. Available: http://www.noldus.com/.

Pérez Pérez, A., Ybarra Muñoz, J., Blay Cortés, V. \& de Pablos Velasco, P. 2007. Obesity and cardiovascular disease. Public health nutrition, 10, 1156-1163. 
Phillips, K., Wood, F. \& Kinnersley, P. 2013. Tackling obesity: the challenge of obesity management for practice nurses in primary care. Family Practice.

Phillips, K., Wood, F. \& Kinnersley, P. 2014. Tackling obesity: the challenge of obesity management for practice nurses in primary care. Fam Pract, 31, 51-9.

Pischon, T., Nothlings, U. \& Boeing, H. 2008. Obesity and cancer. Proc Nutr Soc, 67, 128-45.

Potter, M. B., Vu, J. D. \& Croughan-Minihane, M. 2001. Weight management: what patients want from their primary care physicians. Journal of Family Practice, 50, 513-519.

Rahmouni, K., Correia, M. L. G., Haynes, W. G. \& Mark, A. L. 2005. Obesity-Associated Hypertension: New Insights Into Mechanisms. Hypertension, 45, 9-14.

Royal College of General Practitioners. 2011. PSQ for workplace based assessment [Online]. Available: http://www.rcgp.org.uk/gp-training-and-exams/mrcgp-workplace-based-assessmentwpba/psq-for-workplace-based-assessment.aspx.

Sciamanna, C. N., Tate, D. F., Lang, W. \& Wing, R. R. 2000. Who reports receiving advice to lose weight? Results from a multistate survey. Arch Intern Med, 160, 2334-9.

Scott, J. G., Cohen, D., DiCicco-Bloom, B., Orzano, A. J., Gregory, P., Flocke, S. A., Maxwell, L. \& Crabtree, B. 2004. Speaking of weight: how patients and primary care clinicians initiate weight loss counseling. Preventive medicine, 38, 819-827.

Scottish Government. 2012. Obesity Indicators 2012 Statistical Bulletin - Health \& Care Series. Steel, D. \& Cylus, J. 2012. United Kingdom (Scotland): Heath System Review Health Systems in Transition.

Street, R. L., Gordon, H. \& Haidet, P. 2007. Physicians' communication and perceptions of patients: Is it how they look, how they talk, or is it just the doctor? Social science \& medicine, 65, 586-598.

Talen, M. R. \& Mann, M. M. 2009. Obesity and mental health. Primary Care: Clinics in Office Practice, 36, 287-305.

Tan, D., Zwar, N. A., Dennis, S. M. \& Vagholkar, S. 2006. Weight management in general practice: what do patients want? Medical journal of Australia, 185, 73.

Tham, M. \& Young, D. 2008. The role of the General Practitioner in weight management in primary care - a cross sectional study in General Practice. BMC Family Practice, 9, 66.

Themessl-Huber, M., Humphris, G., Dowell, J., Macgillivray, S., Rushmer, R. \& Williams, B. 2008. Audio-visual recording of patient-GP consultations for research purposes: a literature review on recruiting rates and strategies. Patient Educ Couns, 71, 157-68.

van Dillen, S., Noordman, J., van Dulmen, S. \& Hiddink, G. 2013. Examining the content of weight, nutrition and physical activity advices provided by Dutch practice nurses in primary care: analysis of videotaped consultations. European journal of clinical nutrition.

Vermeire, E., Hearnshaw, H., Van Royen, P. \& Denekens, J. 2001. Patient adherence to treatment: three decades of research. A comprehensive review. Journal of Clinical Pharmacy and Therapeutics, 26, 331-342.

World Health Organisation. 2012. World Health Statistics 2012.

Zhou, Y., Collinson, A., Laidlaw, A. \& Humphris, G. 2013. How Do Medical Students Respond to Emotional Cues and Concerns Expressed by Simulated Patients during OSCE Consultations? - A Multilevel Study. PLoS ONE, 8, e79166. 